\title{
Congratulations to our colleagues at Open Medicine
}

\author{
Matthew B. Stanbrook MD PhD, Ken Flegel MDCM, Barbara Sibbald BJ, Eric Wooltorton MD, \\ Noni McDonald MD MSc, Amir Attaran LLB PhD, Paul C. Hébert MD MHSc, on behalf of the staff of CMAJ
}

$\mathrm{O}$ n Apr. I8, 2007, the world of medical publishing became larger with the debut of Open Medicine, a new online-only general medical journal. We welcome the arrival of a new venue that shares $C M A{ }^{\prime}$ 's objective of providing timely dissemination of research findings and clinical knowledge to as broad a community as possible. ${ }^{1}$ If successful, this new journal will be a positive development for the world in general and Canada in particular. With a second general medical journal based in Canada, yet open to the world, there is no good reason why Canadian researchers, who are world leaders in scientific productivity, ${ }^{2,3}$ should have to leave home in order to find a suitable medium for dissemination of their best work.

Like CMAJ, Open Medicine is an open-access journal, available free to all who wish to read it and free for all who wish to contribute to it. As open access remains disappointingly rare among general medical journals (Table I), this is both commendable and of great significance. The birth of Open Medicine thus provides us with a valuable opportunity to remind our readers why open access to the medical literature is important and necessary.

The primary mission of medical journals, the reason for their origin and the justification for their continued existence is the effective and widespread dissemination of medical knowledge, particularly that which is new, important, timely or controversial. It should be obvious that barriers to access, financial or otherwise, directly contradict this mission and impair the basic function of a journal. It therefore seems paradoxical that most of the world's journals, particularly those that historically have had the greatest impact on the biomedical community, continue to feel that their mission is best served by hiding their content behind password-protected firewalls.

Open access creates new opportunities for knowledge dissemination that are not provided by traditional publishing models. The Internet brings readers from around the world to a journal's doorstep, simply by making searching for and retrieving information vastly easier. With its audience no longer limited to a small group of subscribers and their specific interests, an open-access journal gains the ability to publish increased content on more diverse topics. Open access also greatly broadens the ability of stakeholders to participate in discussions about medical science and policy, potentially transforming local peer-group interactions that may drive knowledge translation at the individual level into global peergroup interactions that have the potential to facilitate knowledge translation worldwide.

Open access allows journals to reach an audience that is not just larger, but one that is also substantially more diverse. Access to medical information is also greatly enhanced for non-traditional audiences, including academics outside the biomedical community, patients and other members of the general public. However, open access is equally important for traditional users of medical journals within the health care community, for whom formidable financial barriers remain in the form of subscription and article charges. These financial barriers are not limited to health care workers in developing countries, but pose problems for health care providers everywhere. This problem is fuelled by the enormous and continuing growth of the medical literature and of the number of journals that publish it. According to the latest data

\section{Key points}

- CMAJ provides free open access to all journal content, similar to Open Medicine and PLoS Medicine but different from most journals

- Open access, compared to restricted access, creates greater opportunities for knowledge dissemination by medical journals

- The Internet provides a novel approach for accessing information and provides it to a much larger and more remote audience

- Science is considered a public good. Major government agencies are adopting open-access rules for the research they fund

from the US National Library of Medicine, the number of articles published in medical journals in 2006 totalled over I4.I million, compared with ro.8 million in 2000. Over the same time period, the number of journals indexed in MEDLINE increased from 4332 to $5020 .{ }^{4}$ Thus, year after year, users of medical literature have more information available and must look in more places to find it. For an individual user to purchase subscriptions or articles from so many sources in order to stay current is not practical or sustainable. Moreover, many health care workers, especially in community-based settings, do not have access to large institutional libraries. Even large libraries are finding it increasingly challenging to maintain comprehensive collections in the face of this rapid expansion. It is not surprising, therefore, that institutions are increasingly endorsing open access as a remedy. ${ }^{5}$

As we at $C M A J$ have observed, ${ }^{6}$ open access has transformed the habits and expectations of scientific publishing.

\footnotetext{
Matthew Stanbrook is Deputy Editor, Scientific; Ken Flegel is Senior Associate Editor; Barbara Sibbald is Deputy Editor, News and Humanities; Eric Wooltorton is Associate Editor; Noni McDonald is Section Editor, Public Health; and Paul Hébert is Editor-in-Chief of CMAJ. Amir Attaran is a member of CMAJ's Editorial-Writing Team and holds the Canada Research Chair in Law, Population Health and Global Development Policy, Institute of Population Health and Faculties of Law and Medicine, University of Ottawa, Ottawa, Ont.
} 
The Internet, one of the most influential advances in communication technology, has had a parallel rapid and profound impact on the culture of biomedical research and clinical practice. The potential to access the world's medical literature almost instantly from one's desk has revolutionized information-seeking behaviour for clinicians and researchers alike. The practical ability of the Internet to fulfill this need has led its users to expect that it continue to be readily and increasingly available. This underscores why those within the open-access movement believe that open access is "a revolution that now seems unstoppable." In the modern area, when access to medical information routinely occurs using
2Ist-century technology, it seems grotesquely inappropriate for journals to publish this information with attitudes and operational models that originated in the igth century.

Arguments against open access are often based on the need for journals to support themselves through subscription fees. The example of the BMJ, which abandoned its openaccess model in 2005 due to declining revenues, ${ }^{8}$ illustrates the basic need for all journals, whether open access or not, to operate under a sound business plan. Nevertheless, such arguments underestimate the capacity for motivated journals to find successful strategies for open-access publishing, as illustrated by CMAJ. Moreover, such economic protests fail to

Table 1: Policies for online access to journal content for CMAJ, other top ten general and internal medicine journals as ranked by 2005 journal impact factor, and Open Medicine

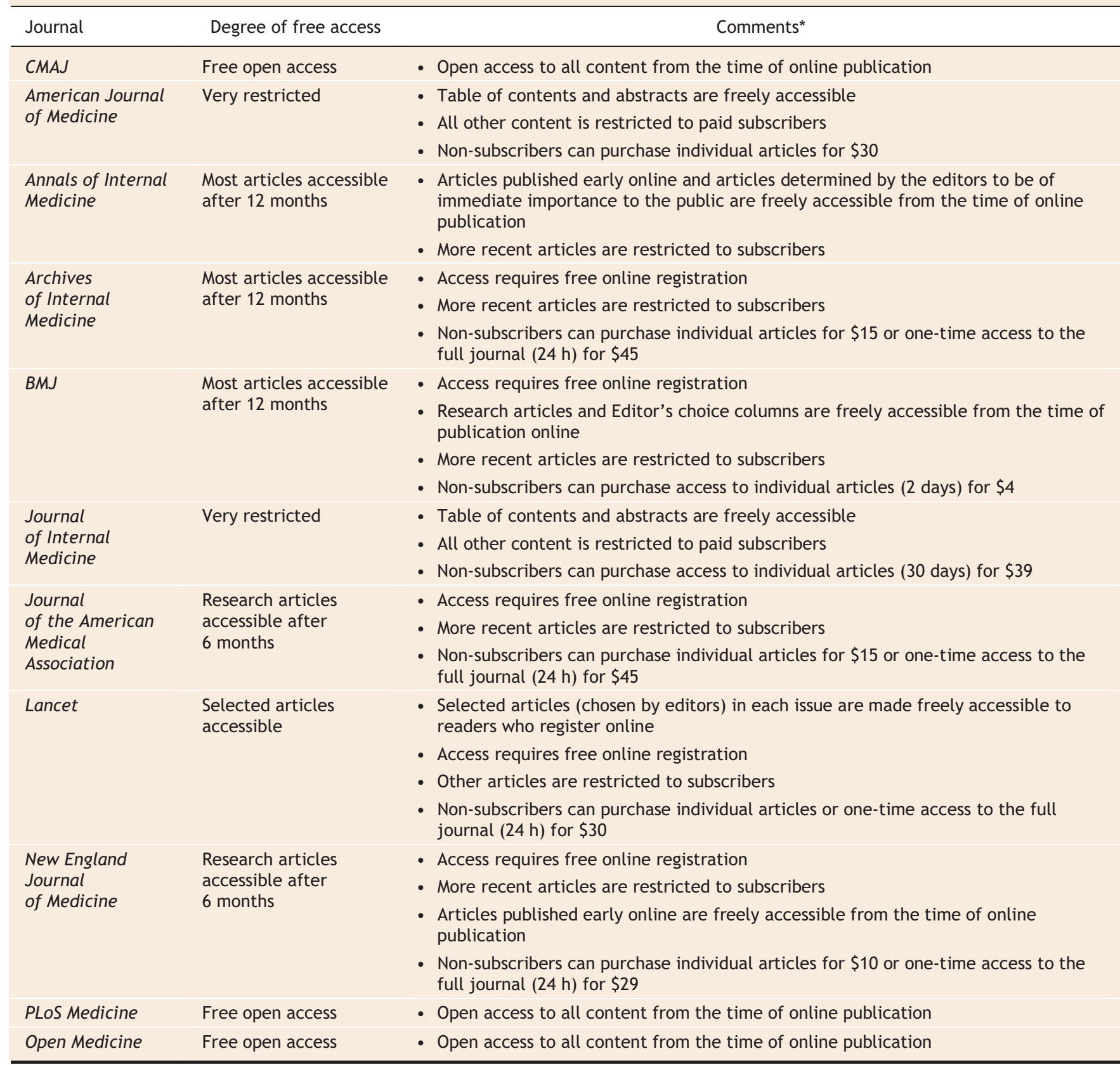

*All funds are in US dollars. 
consider that the true value of scientific information is ultimately determined by its dissemination and impact, not by its price. Few people would deny that information has a commercial value, yet many people also acknowledge that health care and science information is of such great importance to society that it cannot be treated merely as a commodity. Canada and other countries already recognize this principle in other ways, such as by the provision of universal access to public health care. When journals have the ability to allow physicians to provide better care, yet continue to create barriers that force clinicians and researchers to rely on outdated information, we can no longer be satisfied with a situation in which the content of most of the world's journals remains locked away from the people best equipped to use it.

Science is a public good, as is the health of individuals and populations. It is increasingly recognized that the results of publicly funded research must be publicly available. The US National Institutes of Health ${ }^{9}$ and the UK Medical Research Council ${ }^{10}$ now require that any published results from research that they fund be posted on an open-access forum. A draft policy of the Canadian Institutes of Health Research makes a similar recommendation. ${ }^{11}$ Even research funded by the private sector, such as the pharmaceutical industry, does not take place without public support. Many industrysponsored trials are coauthored by academic researchers who are based at public institutions and who thereby derive their positions and credentials from public sources. Moreover, all clinical trials depend on the voluntary participation of members of the public. To the extent that biomedical research cannot take place without public participation, the public should be entitled to access this research.

Starting up a new medical journal from scratch poses tremendous challenges that are not for the faint of heart. Open Medicine is fortunate to have an experienced editorial team of talented and creative people. We at CMAJ know this first-hand because many of these same individuals, we are proud to acknowledge, are former members of our team. Indeed, it was the prudent decisions and hard work of some of these individuals that made CMAJ the world's leading openaccess general medical journal.

We congratulate our friends at Open Medicine on their achievement and wish them the very best of luck with this new venture.

Competing interests: Amir Attaran is a member of $C M A$ Fs Editorial-Writing Team and previously served on the CMAJ governance panel. All other authors are editors and are salaried employees of CMAJ.

Contributors: All of the authors contributed to the writing and revising of the article and approved the version to be published.

\section{REFERENCES}

I. Maskalyk J, for the Editors of Open Medicine. Why Open Medicine? Open Med 2007; I:EI-2

2. Falagas ME, Michalopoulos AS, Bliziotis IA, et al. A bibliometric analysis of published research in several biomedical fields, I995-2003. CMAJ 2006;175:1389-90.

3. Michalopoulos A, Falagas ME. A bibliometric analysis of global research production in respiratory medicine. Chest 2005; I28:3993-8.

4. United States National Library of Medicine. Detailed indexing statistics 1965-2006. Bethesda (MD): National Institue of Health; 2007. Available: www.nlm.nih.gov/bsd/index_stats_comp.html (accessed 2007 June 4).

5. Canadian Library Association. Submission to SSHRC consultation on open access. Ottawa: The Association; 2005. Available: www.cla.ca/issues/SSHRC_Open \%20Access_Final.pdf (accessed 2007 June 4).

6. Moving forward with CMAJ.ca [editorial]. CMAJ 2005;I73:II3I.

7. Yamey G, Barbour V, Cohen B, et al. The joys and challenges of being an open-access medical journal. Open Med 2007; I:E46-8.

8. Sullivan P. Free-access era coming to an end at eBMJ. CMAJ 2003;169:590.

9. National Institutes of Health (NIH). Policy on enhancing public access to archived publications resulting from NIH-funded research. Bethesda (MD): NIH; 2005. Available: http://grants.nih.gov/grants/guide/notice-files/NOT-OD-05-022.html (accessed 2007 June 4).

Io. Mayor S. Publicly funded research in the UK must be freely accessible. BMJ 2006; 333:I12.

II. Canadian Institutes of Health Research. Draft policy on access to CIHR-funded research outputs. Available: www.cihr-irsc.gc.ca/e/32326.html (accessed 2007 June 4).

Correspondence to: Dr. Matthew Stanbrook, CMAJ, I867 Alta Vista

Drive, Ottawa ON KIG 3 Y6; matthew.stanbrook@cma.ca

\section{Holiday Review 2007 Call for submissions}

Hilarity and good humour ... help enormously in both the study and the practice of medicine ... [I]t is an unpardonable sin to go about among patients with a long face. - William Osler

Quirky, contentious or simply fun - we want it all! Yes, it's time to send us your creative missives for CMA's Holiday Review 2007. We're looking for humour, spoofs, punchy personal reflections and off-beat scientific explorations.

Please submit online (at http://mc.manuscriptcentral.com/cmaj). Articles should be no longer than 1200 words; photographs and illustrations are welcome. Mention in your cover letter that your submission is intended for this year's Holiday Review.

The deadline for submissions is Oct. 1, 2007.

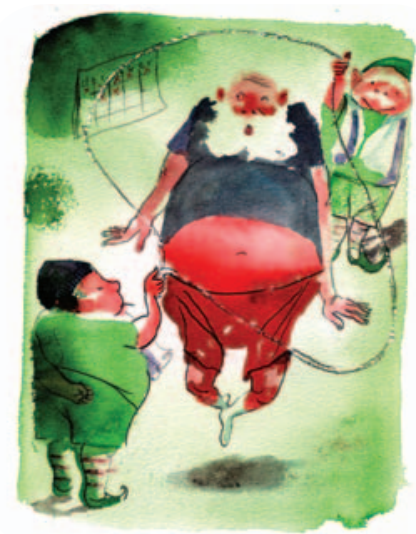

